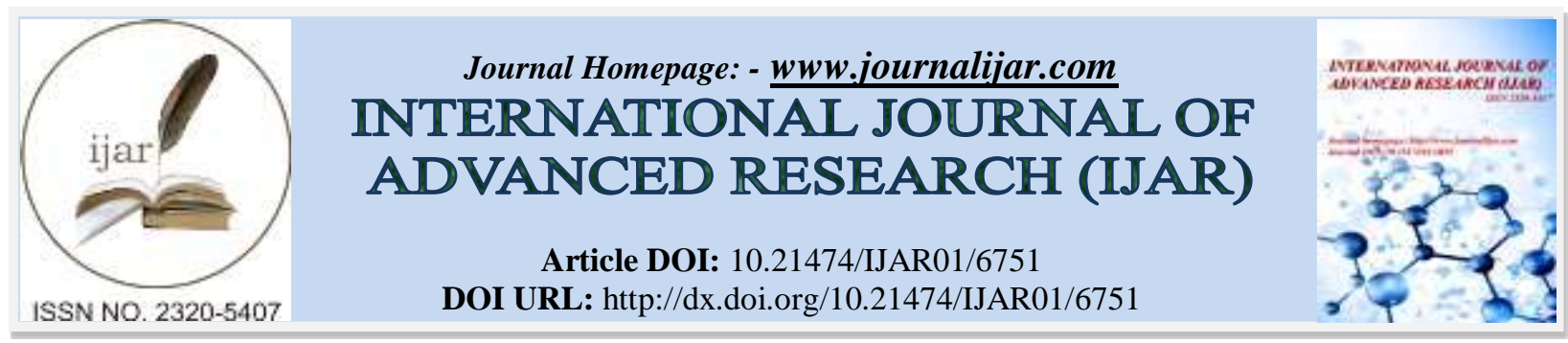

RESEARCH ARTICLE

\title{
FULL MOUTH REHABILITAION OF WORN DENTITION USING PANKEY MANN SCHUYLER TECHNIQUE \& BROADRICK FLAG METHOD- A CASE REPORT.
}

\author{
Dr. Kiran Kaushik ${ }^{1}$, Dr. Pankaj Dhawan, MDS$^{2}$, Dr. Pankaj Madhukar, MDS ${ }^{3}$, Dr. Piyush Tandan, MDS $^{3}$, \\ Dr. Shivam Singh Tomar ${ }^{4}$ and Dr. Divyesh Mehta ${ }^{4}$. \\ 1. Post graduate student, Department of Prosthodontics, MRDC. \\ 2. Professor and Head of Department of Prosthodontics, MRDC. \\ 3. Professor, Department of Prosthodontics, MRDC. \\ 4. Senior Lecturer, Department of Prosthodontics, MRDC.
}

\section{Manuscript Info}

Manuscript History

Received: 15 January 2018

Final Accepted: 17 February 2018

Published: March 2018

Keywords:-

Pankey Mann Schuyler Philosophy, Full Mouth Occlusal Rehabilitation, Anterior Guidance.

\begin{abstract}
Full mouth rehabilitation is a biggest challenge to any prosthodontist in the restorative dentistry. It requires detailed diagnosis and efficient treatment planning to achieve occlusal contacts that are in harmony in order to optimize stomathognathic function, health and esthetics. This gives a patient utmost comfort and satisfaction. Prosthodontic management of occlusal wear problems is very much difficult and demanding task on the part of the prosthodontist. Various factors such as vertical dimension of occlusion, centric relation, occlusal contact pattern, esthetics and phonetics must be considered simultaneously for both anterior and posterior teeth when the occlusion is rehabilitated. This may be further complicated by existing restorations, pulpal exposure, missing teeth and tooth sensitivity. Several techniques of full mouth rehabilitations are available and a clinician should ascribe to one after a comprehensive diagnosis of the patient's clinical condition and prospective consideration of his/her oral health, function, comfort and esthetic requirements.
\end{abstract}

Copy Right, IJAR, 2018,. All rights reserved.

\section{Introduction:-}

Full mouth rehabilitation seems to be a challenging treatment modality which is liable to improve the appearance of the patient and corrects occlusal imperfections. Vertical dimension, centric relation, speech and muscle tone are essential fundamentals of full mouth rehabilitation. The goal of dentistry is to increase the life span of the functioning dentition, just as the goal of medicine is to increase the life span of functioning individual. ${ }^{1}$ There is a need to analyze each aspect carefully with regard to existing natural dentition and its relationship with the stomatognathic system. Full mouth rehabilitation tends to create smile that is not only esthetic but also functionally comfortable. $^{2}$

Attrition of teeth is commonly seen in routine clinical examination. Many a times patients are unaware about the ongoing process of attrition as the main etiology is stress and it generally happens in an unconscious state and patient realizes it only when sufficient loss of teeth structures has already occurred. ${ }^{3}$ Various factors such as vertical dimension of occlusion, centric relation, occlusal pattern, esthetics and phonetics needs to be considered 
simultaneously for both anterior and posterior teeth during rehabilitation. This may be further complicated by existing restorations, pulpal exposure, missing teeth, tooth sensitivity, supra erupted teeth and TMJ pain. ${ }^{4}$

This case report describes a clinical case of wear, treated prosthetically using Pankey Mann Schuyler philosophy.

\section{Case:-}

A healthy 48-year-old female patient reported to the Department of Prosthodontics, Manav Rachna Dental College, Faridabad with a chief complaint of difficulty in chewing from both sides of jaw, and sour taste while chewing with clinically generalized sensitivity of teeth. The patient's dental history indicated periodic dental examination and treatment to be done included oral prophylaxis, re- RCT in relation to 34 and 44, post and core in relation to 38 , rerestoration in relation to 25 , prosthesis removal in relation to $15,16,17,18 ; 27 ; 34,35,36,37,38$ and $44,45,46,47,48$. The patient denied any symptoms of temporomandibular joint disorder or myofacial pain dysfunction.

An initial evaluation indicated decreased vertical dimension of about $4 \mathrm{~mm}$. Oral hygiene was average with no symptoms of periodontal affliction. Clinical and radiographic examination and diagnostic cast's revealed attrition resulting in reduced clinical crown length, especially pronounced in anterior teeth.

The PMS philosophy aims at achieving the following principles of occlusion advocated by Schuyler. ${ }^{5}$

a. Coordinated and static contacts of the maximum number of posterior teeth in centric relation position of the mandible.

b. Functionally harmonious anterior guidance during the lateral excursive movements.

c. Disclusion of the posterior teeth during protrusion determined by the anterior guidance.

d. Absence of interferences during lateral excursions on the non-working side.

e. Group function on the working side during the lateral excursions.

\section{Clinical Steps:-}

1. Impressions, facebow transfer, mounting of maxillary cast using facebow, centric record by lucia jig, mounting of mandibular cast by centric record, occlusal plane analysis and mock wax-up at increased vertical dimension and occlusal splint at increased vertical dimension.

2. Mandibular anteriors preparation followed by temporization and cementation

3. Maxillary anteriors preparation followed by temporization and cementation.

4. Mandibular posteriors preparation followed by temporization

5. Maxillary posteriors preparation by functionally generated pathway technique followed by temporization

6. Final cementation of mandibular posteriors and maxillary posteriors.

\section{Clinical Protocol:-}

As there was loss of vertical dimension, restoration of the vertical dimension was first considered. Diagnostic impression was taken with irreversible hydrocolloid. Maxillary cast was mounted on articulator, using Facebow transfer and mandibular cast was mounted using centric relation record. Centric record was made by lucia jig. All the deflective contacts were checked and removed from the cast. Broadrick flag analysis was done to determine the occlusal plane. Mock up was done. Using this mock up, temporaries were fabricated by self cure acrylic resin (DPI RR Cold cure, India)by raising the vertical dimension around $4 \mathrm{~mm}$. The patient was asked to wear the temporaries for 3 weeks. After one week, the patient reported that she did not have any difficulty adapting to the new centric relation. The patient was asked to visit every alternate week for three weeks. As the patient got comfortable with the centric relation, so we initiated the further treatment.

First, the lower anterior teeth were prepared. Impressions of the prepared teeth was made with irreversible hydrocolloid in stock trays. All the temporaries were in place so we were getting proper interocclusal space to build lower anteriors. Coping trials were done and then final cementation of porcelain fused metal prosthesis was done. Lower lip line was assessed for optimum visibility. After mandibular anterior cementation, we proceeded with the maxillary anteriors. Coping trial was done and at the time of bisque trial speaking line, smile line and visibility was assessed. Occlusal plane was established by using Broadrick flag. ${ }^{6}$ Then posterior teeth were prepared and Provisional restorations were cemented in harmony with anterior guidance followed by the preparation of the upper posterior teeth. Upper posterior teeth were temporized. Upper posteriors were fabricated using functionally generated pathway. Lower posterior and upper posterior were cemented together. All the centric, lateral and protrusive interferences were eliminated. Canine guided occlusion concept was opted for the patient rehabilitation. 
Oral hygiene instructions were given. The patient was followed up after one week. Patient was instructed to report every month upto 6 months then once in a 6 month. The patient was pleased with esthetics, function, and comfort of the prostheses.

\section{Discussion:-}

Rebuilding of severely attrited dentition has been a challenge to a dentist's skill and capabilities. The concept of complete mouth rehabilitation is dependent upon three proved and accepted principles. These are; the existence of a physiological rest position of the mandible which is constant, the recognition of a variable vertical dimension of occlusion and the acceptance of a dynamic, functional centric occlusion. ${ }^{7}$ Occlusal rehabilitation seeks to convert all unfavourable forces on the teeth which inevitably induce pathologic conditions, into favourable forces which permit normal function and therefore induce healthy conditions. ${ }^{1}$ Many clinical studies indicate that, vertical dimension of occlusion is maintained even with the rapid wear. As the occlusal surface wears, compensatory alveolar process elongates by progressive remodeling of the alveolar bone. ${ }^{8}$ The three prime requirements of full mouth rehabilitation are healthy TMJ, harmonious anterior guidance and non-interfering posteriors. These three factors are interrelated and presence of any disharmony between these will affect the stomatognathic system. There are many philosophies to follow for an occlusal rehabilitation, but the most important among them is Hobo's philosophy and Pankey Mann Schuyler philosophy. Pankey Mann Schylur philosophy is one of the most practical philosophies for occlusal rehabilitation. It is well organized logical procedure that progresses smoothly with less wear and tear on the patient operator and technique. ${ }^{9}$ Pankey and Mann introduced an instrument for occlusal plane analysis, here we used simplified version of the instrument i.e. customized broad rick flag analyzer. This assists in the reproduction of tooth morphology that is commensurate with the curve of Spee when posterior restorations are designed. ${ }^{10}$ The anterior teeth are usually restored first so as to achieve functional and esthetically viable anterior guidance. Anterior guidance is the dynamic relationship of the lower anterior teeth against the upper anterior teeth through all ranges of function. Anterior guidance plays a very important role in full mouth rehabilitation following centric relation. ${ }^{11}$ Anterior guidance forms the anterior control to provide posterior disclusion. The three main things to be taken care of, while replacing posterior teeth, are achieving posterior disclusion, establishing the plane of occlusion and deciding the type of occlusal scheme. Disclusion refers to separation of opposing teeth during eccentric movements of mandible, as reported by Christensen. ${ }^{12}$ A proper plane of occlusion permits the disclusion of all the teeth on the balancing side when the mandible is moved laterally. The reconstruction of vertical dimension of occlusion should be done at the centric relation and it should be acceptable for the patient at the neuro-muscular level. ${ }^{13}$ Pankey Mann Schyuler's philosophy advocates that condylar guidance does not dictate anterior guidance. Thus it believes in harmonization of the anterior guidance for best possible esthetics, function and comfort and the determination of an occlusal plane based on anterior guidance. Occlusal rehabilitation is a radical procedure and should be carried out in accordance with the dentist's choice of treatment based on his knowledge of various philosophies followed and clinical skills. ${ }^{14}$ The PMS technique is a very flexible concept. According to Dawson ${ }^{7}$ the most impressive advantage of PMS is the latitude it permits. The advantages of this technique include incorporation of freedom from centric, no need to prepare or rebuilding all the teeth at a time, a well-organised procedure, all posterior occlusal contours are programmed in harmony with both condylar border movements and a perfected anterior guidance, and there is no need of any specific instrument unlike Hobo's technique.

\section{Conclusion:-}

The key to success is a multidisciplinary treatment approach and constant communication with patients to make them understand the disorder and proactively participate in treating it ${ }^{15}$. Whenever treating severely worn teeth, an anterior guidance should be established in harmony with functional jaw movements and all posterior teeth should discluded during any eccentric jaw movement. A detailed diagnosis and treatment planning is necessary to achieve predictable success. The restoration of normal healthy function of the masticating apparatus is the ultimate aim of full mouth rehabilitation. By following Pankey Mann Schuyler philosophy the treatment can be completed more quickly and easily and with much more comfort for the patient. The patients appreciate anything which expedites having their work finished faster so that they can enjoy the oral health, comfort, functional efficiency and esthetics which are prime objectives of oral rehabilitation. ${ }^{16}$ 


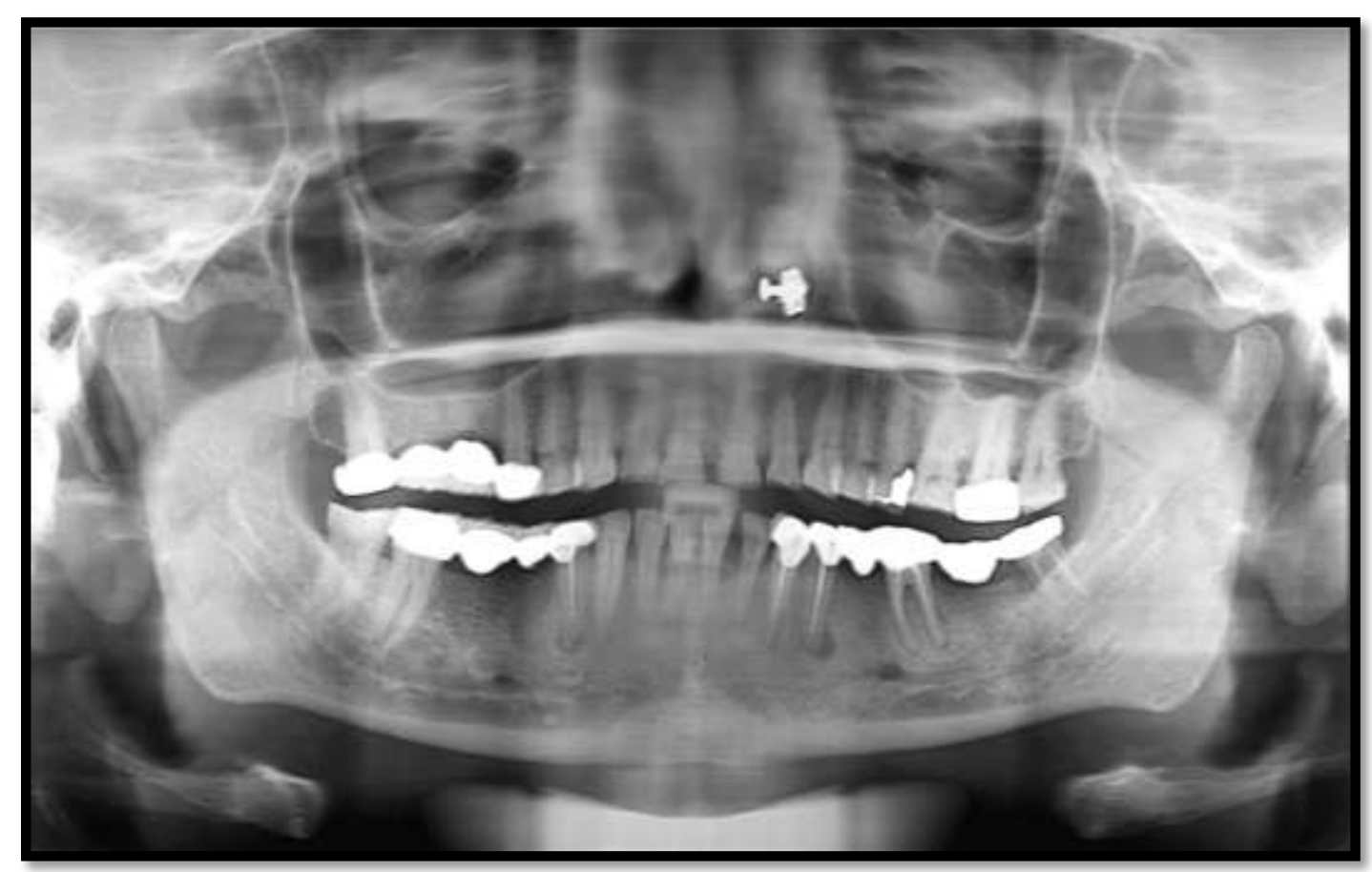

Fig1:- Pre-operative OPG

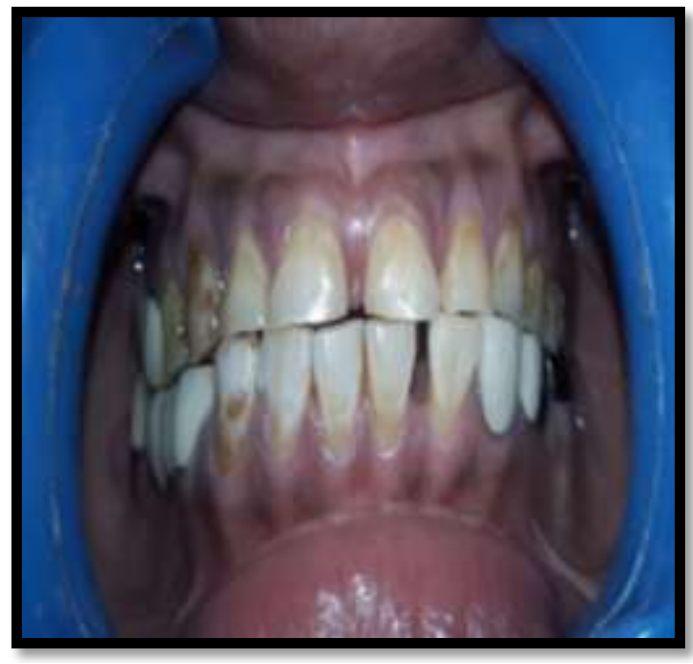

Fig2:-Pre-op occlusion

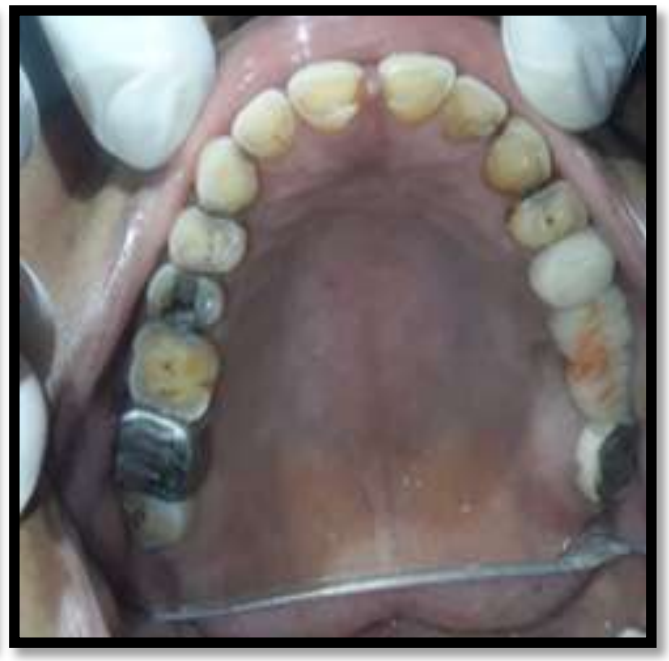

Fig3:- Pre-op maxillary teeth

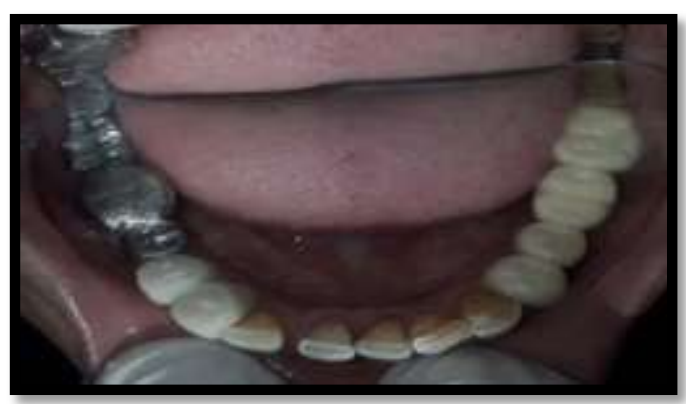

Fig4:- pre-op mandibular teeth 


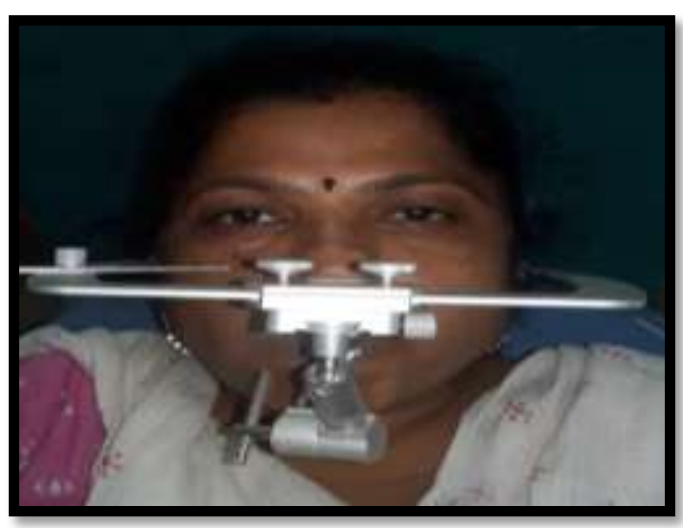

Fig5:- Facebow record

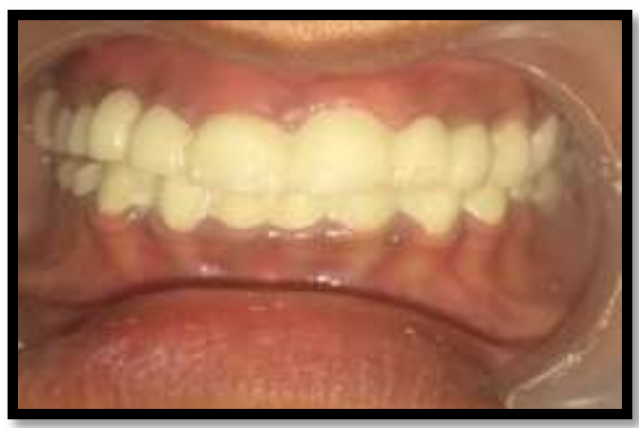

Fig6:- Temporaries cemented

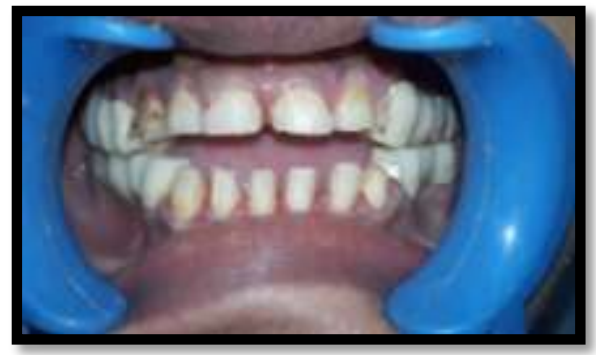

Fig7:-Mandibular anteriors pepared

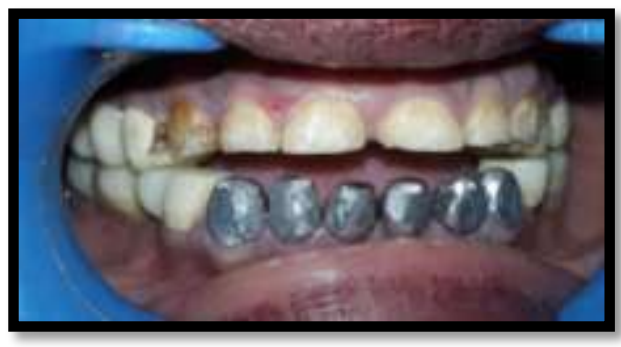

Fig8:-Coping trial 


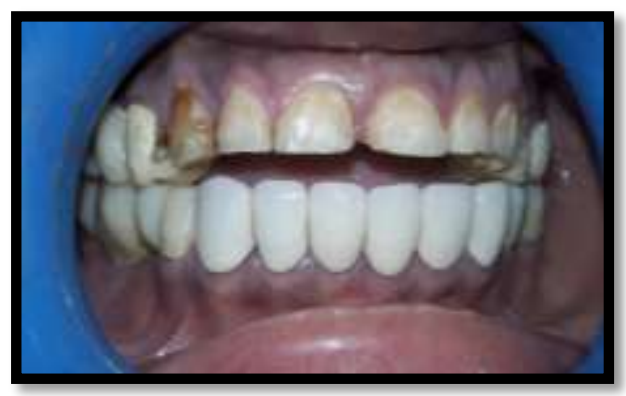

Fig9:- Mandibular anterior cementation

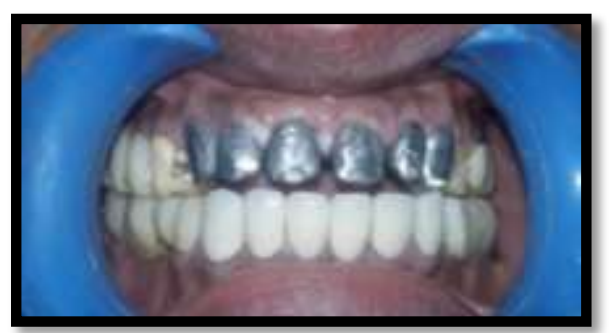

Fig10:- Maxillary anteriors coping trial

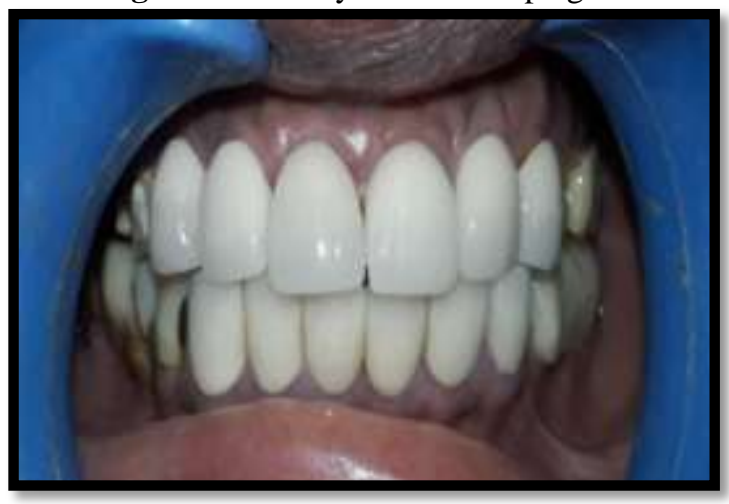

Fig11:-Maxillary anterior cementation

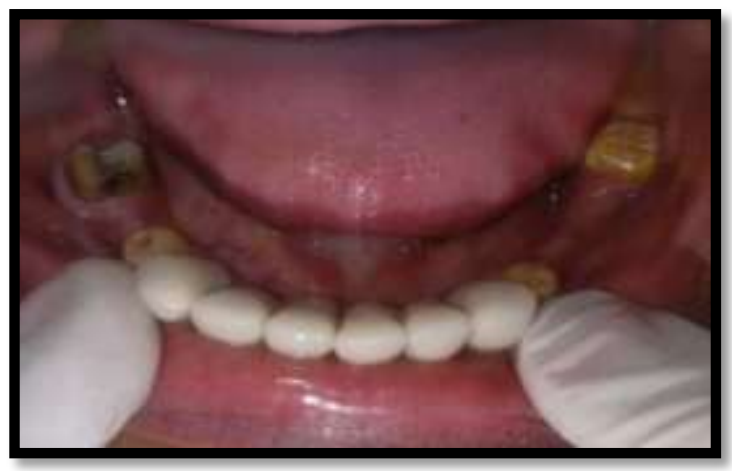

Fig12:- Mandibular posteriors prepared 


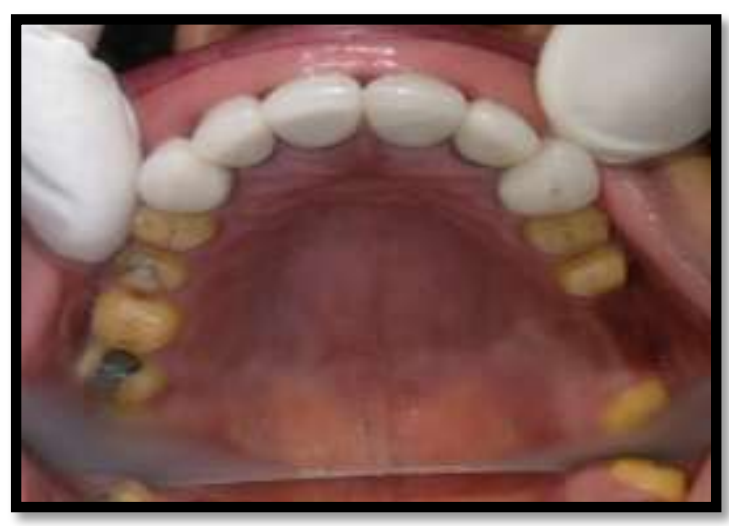

Fig13:-Maxillary posteriors prepared

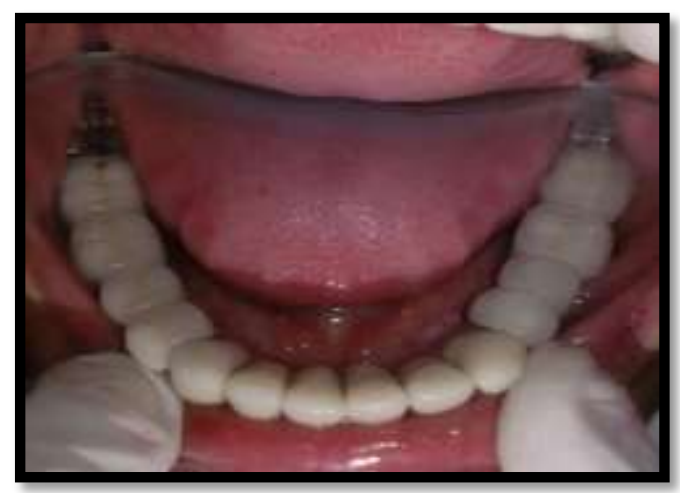

Fig.14:- Mandibular posteriors cemented using anterior guidance

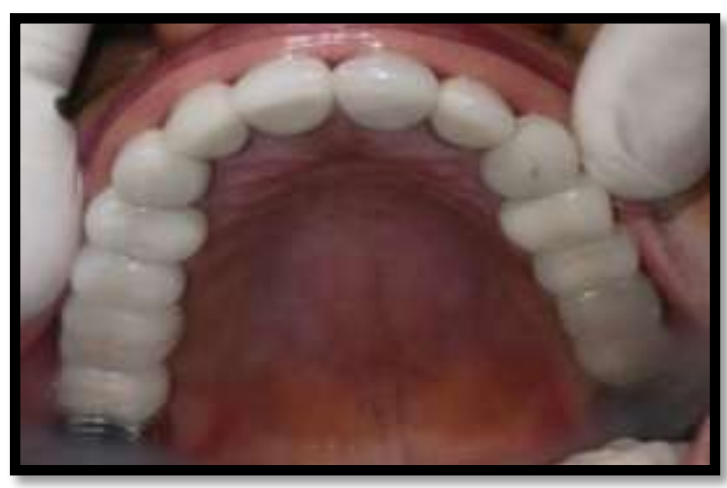

Fig15:- Maxillary posteriors cemented using FGP technique

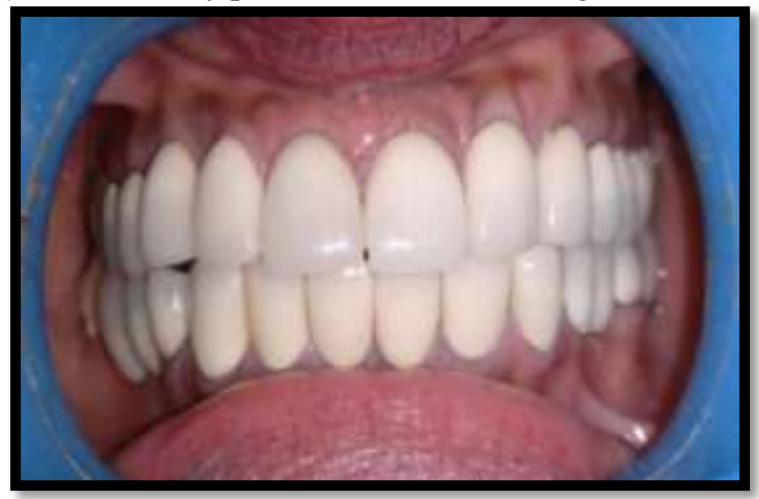

Fig16:- Post-op front view. 


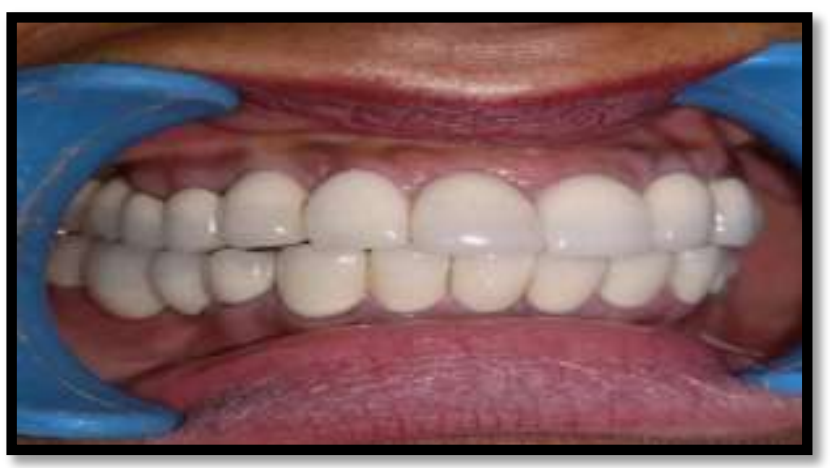

Fig17:-Post-op right lateral view.

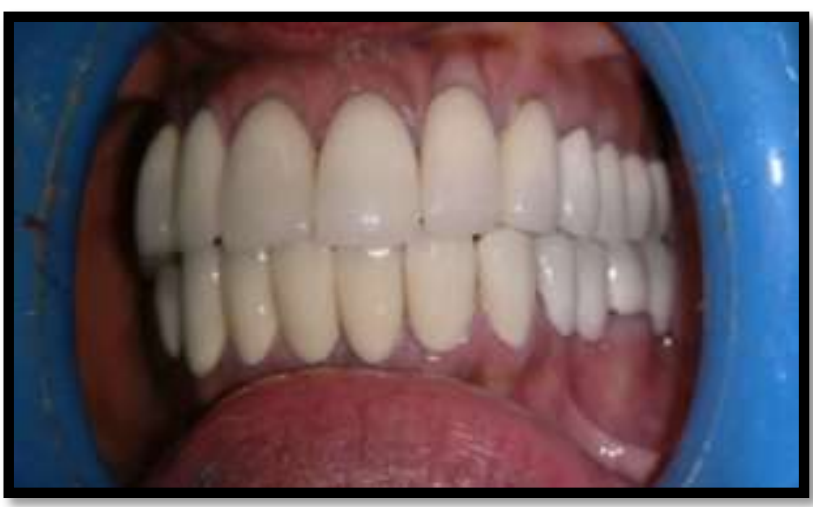

Fig18:- Post-op left lateral view

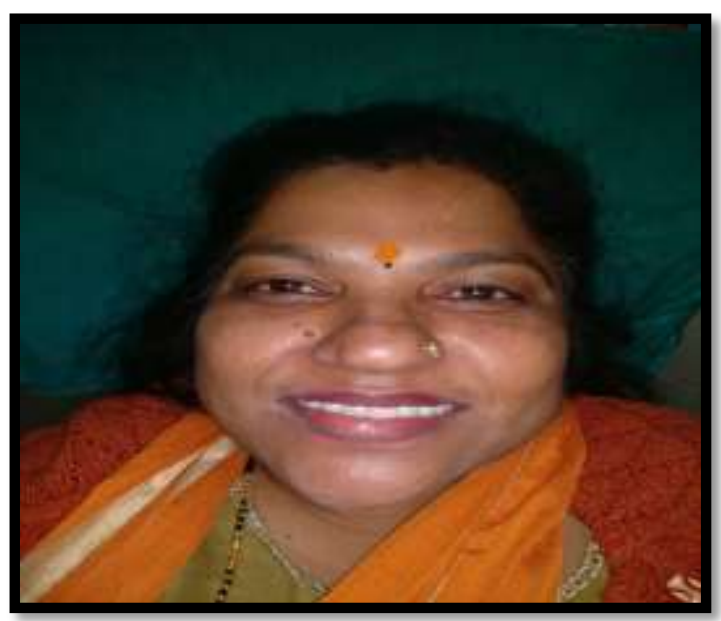

Fig19:- Post-op view of patient 


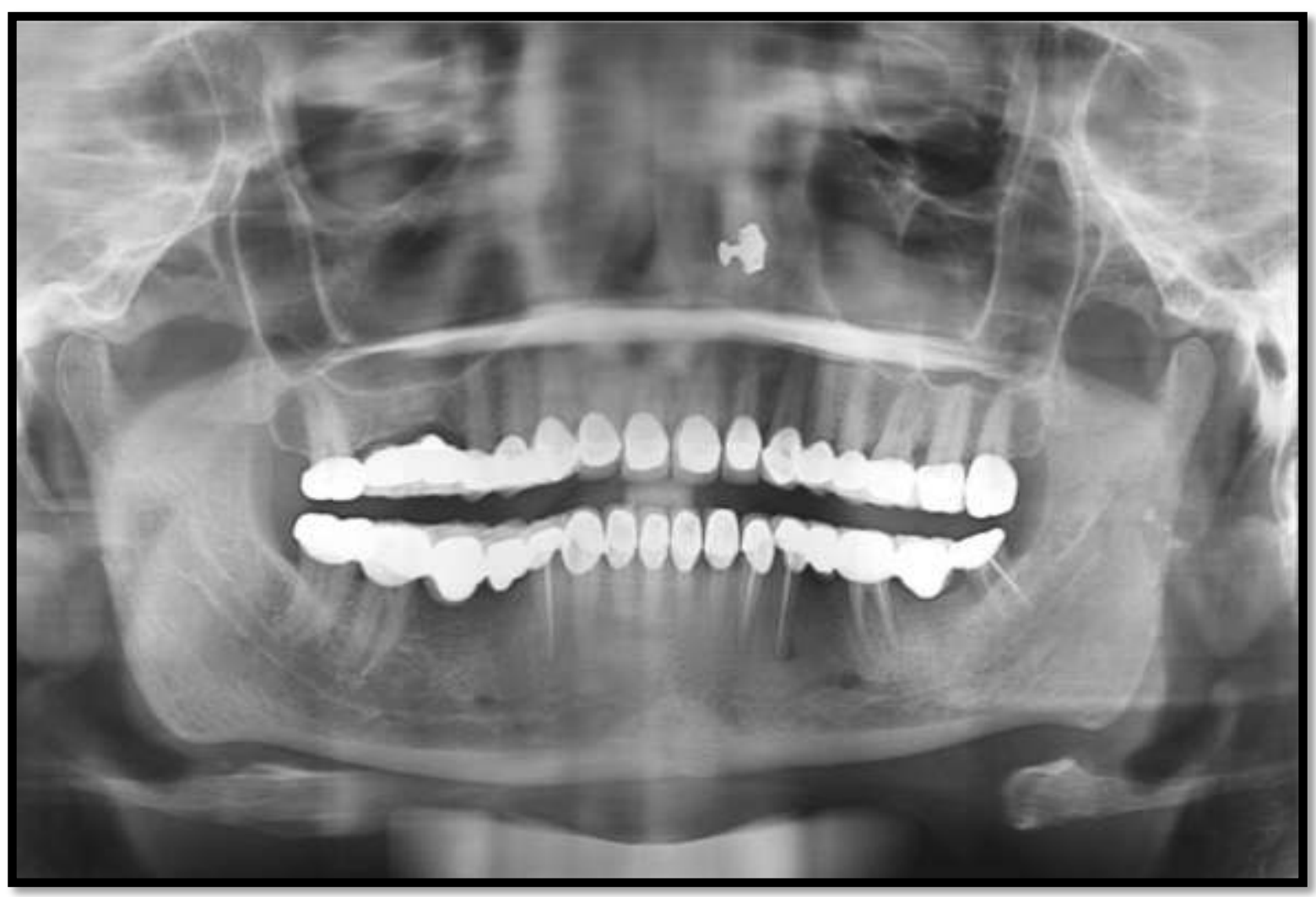

Fig20:- Post-op OPG

\section{References:-}

1. Irving Goldman. The goal of full mouth rehabilitation. J pros Dent 1952;2:246-251.

2. Dawson PE. Functional occlusion from TMJ to smile design. Mosby St. Louis, Elsevier. 2007:18-26, 27-32, 7583, 429-52.

3. Devassy PJ etal. Full mouth occlusal rehabilitation; by Pankey Mann Schuyler philosophy. Annals of Prosthodontics \& Restorative Dentistry, January-March 2017:3(1):29-33.

4. Manoj Shetty, Niranjan Joshi et al. Complete Rehabilitation of a patient with occlusal wear. A case report. Journal of Indian Prosthodontic Society 2012;12:191-197.

5. Turner KA, Missirlian DM. The P.M. philosophy of occlusal rehabilitation. Dent Clin North Am 1963;7:621-38.

6. Lynch CD, McConnell RJ. Prosthodontic management of the curve of Spee: use of the Broadrick flag. J Prosthet Dent 2002;87(6):593-7

7. Chirag $\mathrm{C}$ etal. Full mouth rehabilitation in a case of severely attrided dentition- a case report. Journal of Evolution of Medical and Dental Sciences/Volume1/ Issue4/October - 2012 Page 610

8. Dawson PE .Evaluation, diagnosis and treatment of occlusal problems. 1989, 2 Ed. Cv Mosby Company, St. Louis Baltimore, Toronto. 56-71.

9. Evaluation, diagnosis and treatment planning of occlusal problems- 2nd edition by Peter E Dawson. Page no. 262.

10. Christopher D Lynch, Robert J Mc Connell. Prosthodontic management of the curve of spee: use of the broadrick flag. J Prosthet Dent 2002;87:593-7.

11. Dawson PE. Anterior Guidance. In: Peter E.Dawson. Evaluation, diagnosis and treatment of occlusal problems. 2nd Ed. Cv Mosby Company, St. Louis Baltimore,Toronto. 1989;274-297.

12. Pokorny PH, Wiens JP, Litvak H. Occlusion for fixed prosthodontics: a historical perspective of gnathological influence. J Prosthet Dent 2008; 99(9):299-313.

13. Bloom DR, Padayachy JN. Increasing occlusal vertical dimension- Why, When and How. Br Dent $\mathbf{J}$ 2006;200(4):199-203. 
14. Sahni SS, Gundawar SM, Radke UM, Deshmukh SP. An appraisal on clinical factors influencing the success of full mouth rehabilitation: a literature review. Int. J Dent Health Sci 2014;1(4):589-600.

15. Shulman J. Teaching patients how to stop bruxing habits. J Am Dent Assoc 2001;132:1275-7.

16. Mann, Pankey. Use of P.M instrument in treatment planning and in restoring the lower posterior teeth. J Pros dent 1960;10:135-150. 